\title{
Mammalian autophagy and the plasma membrane
}

\author{
Mariana Pavel $^{1}$ and David C. Rubinsztein ${ }^{1 *}$
}

${ }^{1}$ Department of Medical Genetics, University of Cambridge, Cambridge Institute for Medical Research, Addenbrooke’s Hospital, Cambridge, UK

*Corresponding author:

David C. Rubinsztein

E-mail: dcr1000@cam.ac.uk

\section{ABBREVIATIONS:}

AJ

AMBRA1

AP2

ATG

E1

E2

E3

ECM

EM

EMT

ER

FA

GABARAP

LIR

NBR1

PAS

PICALM

RE

SNAP

SNARE

TBC1D14

TGN

TJ

VAMP

VPS adherens junction

activating molecule in BECN1-regulated autophagy protein 1

adaptor protein 2

autophagy related gene/protein

ubiquitin activating enzyme

ubiquitin conjugating enzyme

ubiquitin ligase

extracellular matrix

electron microscopy

epithelial-mesenchymal transition

endoplasmic reticulum

focal adhesion

GABA(A) receptor-associated protein

LC3-interacting region

neighbour of BRCA1 gene 1

phagophore assembly site or pre-autophagosomal structure

phosphatidylinositol-binding clathrin assembly protein

recycling endosome

synaptosomal-associated protein

SNAP receptor

TBC1 domain family member 14

trans-Golgi network

tight junction

Vesicle-Associated Membrane Protein

vacuolar protein sorting 
WASH

WASH and Scar homolog

Keywords: autophagy; plasma membrane; endocytosis; recycling endosome; ATG protein

RUNNING TITLE: Mammalian autophagy and the plasma membrane

\begin{abstract}
Autophagy (literally "self-eating") is an evolutionarily conserved degradation process where cytoplasmic components are engulfed by vesicles called autophagosomes, which are then delivered to lysosomes, where their contents are degraded. Under stress conditions, such as starvation or oxidative stress, autophagy is upregulated in order to degrade macromolecules and restore the nutrient balance. The source of membranes that participate in the initial formation of phagophores is still incompletely understood and many intracellular structures have been shown to act as lipid donors, including the endoplasmic reticulum, Golgi, nucleus, mitochondria and the plasma membrane. Here we focus on the contributions of the plasma membrane to autophagosome biogenesis governed by ATG16L1 and ATG9A trafficking, and summarise the physiological and pathological implications of this macroautophagy route, from development and stem cell fate to neurodegeneration and cancer.
\end{abstract}

Introduction to autophagy

Macroautophagy (henceforth autophagy) is an evolutionary conserved intracellular pathway that enables the degradation of proteins, lipids, macromolecular complexes including oligomeric proteins, organelles including mitochondria, and various intracellular pathogens [1]. These substrates are sequestered by double-layered, cup-shaped structures called phagophores, which form 
autophagosomes after their edges extend and join [2]. The completed autophagosomes then traffic along microtubules towards the microtubule-organising centre of the cell where lysosomes are clustered [3]. This brings the autophagosomes into proximity with lysosomes and facilitates their fusion, after which the lysosomal hydrolases can degrade the autolysosomal contents [4].

A key unresolved question in the field is how the double-membraned autophagosomes are sculpted. Various membrane sources have been implicated in the formation of autophagosomes, including the endoplasmic reticulum (ER) [5-7], mitochondria [8], ER-mitochondrial contact sites [9], the Golgi [10], ER exit sites [11, 12] and the plasma membrane [13-15]. Here we will consider how the plasma membrane is involved in autophagy and how autophagy may regulate various signals from the plasma membrane. These discussions do not obviate roles for other membrane sources - indeed, it is our belief that autophagosomes derive their membranes from multiple cellular compartments.

Autophagosome formation is regulated and enabled by many proteins, many of which are known as ATG proteins. Among these 30 or so proteins, a key player is LC3, one of 6 members of the Atg8 family [16]. LC3, like its family members, is translated in a precursor form and becomes LC3-I after its C-terminal is cleaved to expose a glycine residue [17, 18]. It then becomes an ubiquitin-like molecule that can be conjugated via its glycine to the lipid phosphatidylethanolamine (as opposed to a protein) in a reaction enabled by the E1-like enzyme, ATG7 and the E2-like enzyme ATG3 [19]. This conjugation is facilitated by the E3-like activity of the ATG5-12-ATG16L1 complex [20]. This latter complex is formed after the ubiquitin-like conjugation of ATG12 to ATG5 and the complexing of this conjugate with ATG16L1, which is thought to dictate the sites of LC3-lipidation (and hence autophagosome formation). The LC3 lipidation event appears to enable the expansion and closure of the autophagosome membranes. ATG16L1-LC3 double-positive structures are considered to be phagophores, while the ATG16L1 complex is removed from closed autophagosomes, which are ATG16L1-negative and LC3-positive [21]. The final closure stages may involve steps akin to scission (as occurs in endocytosis or multivesicular body formation), rather than simple fusion events [22]. 
In this short review, we will consider how trafficking events from the plasma membrane may regulate autophagosome formation, as well as how autophagy can regulate aspects of biology at the plasma membrane. We will not consider processes like LC3-associated phagocytosis which use some components of the autophagy machinery but are not strictly autophagy.

\section{ATG16L1 traffics from the plasma membrane to sites of autophagosome biogenesis}

ATG16L1 is a cytosolic protein which associates with clathrin-coated pits on the plasma membrane via its interaction with clathrin adaptor protein AP2. If one labels the plasma membrane with various different lipid-binding dyes, these associate first with ATG16L1 and then with LC3-positive autophagosomes, suggesting that the plasma membrane-associated ATG16L1 traffics to sites of autophagosome biogenesis [13]. If clathrin-dependent endocytosis is inhibited, then autophagosome biogenesis is reduced, and if endosomal scission is inhibited, then ATG16L1 accumulates in the scission intermediates. Subsequent studies suggest that ATG16L1 can also be trafficked from the plasma membrane via clathrin-independent forms of endocytosis [23].

After endocytosis, the ATG16L1-positive structures undergo SNARE-dependent homotypic fusion events which increase the size of the resultant vesicles and enhance their ability to acquire LC3. Thus, these homotypic fusion events (which may be complex involving more than one set of SNAREs), enable the conversion of ATG16L1-positive, LC3-negative phagophore precursors into phagophores. Indeed, the EM morphology of some of the fusion products are compatible with what one may expect from early phagophores [15].

\section{ATG9A meets ATG16L1 in recycling endosomes}

ATG9A is a multipass transmembrane protein that is important for autophagosome biogenesis. Its exact roles are poorly understood, but it may assist in bringing membrane to forming phagophores thereby helping them to grow. While LC3-II-positive structures do not form in ATG16-null cells, the 
formation of such structures as well as ATG16L1 vesicles is reduced but not ablated in ATG9Aknockdown cells, and ATG9A appears to associate with autophagosome precursors early in their biogenesis [24]. ATG9A is also associated with clathrin-coated pits at the plasma membrane [14, 25], but is seen in distinct pits from ATG16L1. ATG9A traffics through a conventional route via early endosomes to recycling endosomes where the ATG9A-containing vesicles fuse with the AT16L1containing vesicles in a process regulated by distinct SNAREs from the homotypic fusions of the ATG16L1 vesicles. This fusion event, regulated by VAMP3, is also critical for autophagosome biogenesis. The ATG16L1 vesicles traffic to recycling endosomes bypassing early endosomes, hence different vesicles which contribute to autophagosome biogenesis traffic from different sites on the plasma membrane via different paths to the recycling endosomes where they meet [14] - see Figure 1 . At present it is not clear whether the so-called homotypic ATG16L1-ATG16L1 vesicle fusion events occur before or after the heterotypic ATG16L1-ATG9A fusion events, or whether there is a dependency on the one type of fusion for the other.

Additional regulation of recycling endosome-associated ATG16L1 is mediated by the PX-BAR protein SNX18. After autophagy induction, Atg16L1-positive recycling endosomes redistribute in a Rab11- and SNX18-dependent manner to a perinuclear SNX18-positive region where Atg16L1 enables LC3, recruitment followed by SNX18-mediated membrane remodeling that provides membranes for autophagosome biogenesis [26].

The itinerary of ATG9A may be complex and it appears that ATG9A needs to be maintained in a cycling pool which involves recycling endosomes and the early Golgi, and possibly other compartments. TBC1D14, a negative regulator of autophagy that controls delivery of membranes from RAB11-positive recycling endosomes to forming autophagosomes binds to the TRAPP complex. A model has been proposed the maintenance of this cycling pool, which is required for autophagy, is maintained by the trafficking mediated by TBC1D14 via its interaction TRAPPIII [27]. Interestingly, similar Atg9 trafficking events are regulated by TRAPIII in yeast [28]. 


\section{Physiological regulation}

When cells are exposed to starvation, a primordial autophagy stimulus, there is increased mobility of vesicles emanating from the plasma membrane and increased homotypic and heterotypic fusions [14, 15]. This could be accounted for by the transcriptional upregulation of the actin-remodelling protein Annexin A2 after starvation in tissue culture and in vivo. Annexin A2 transcription is positively regulated by starvation via activation of JNK leading to increased binding of c-Jun to its promoter [29]. Annexin A2 knockdown impairs basal and starvation-induced autophagy, and its overexpression enhances autophagy - hence it is necessary and sufficient for starvation-induction of autophagy [29, 30]. This may be because this protein positively regulates both the endocytosis and homotypic fusion of the ATG16L1-containing vesicles [30], as well as the actin-dependent trafficking of the ATG9Acontaining vesicles from early to recycling endosomes and thus heterotypic fusion [15].

\section{Diseases where ATG16L1 and ATG9A trafficking are perturbed.}

These trafficking events appear to be perturbed by disease-associated genetic variants. The D620N mutation in VPS35 causes a rare autosomal dominant form of Parkinson's disease [31, 32]. This mutation impairs autophagy and leads to the accumulation of alpha-synuclein, an autophagy substrate whose accumulation is pathognomonic for Parkinson’s disease. D620N VPS35 associates poorly with the actin-remodelling WASH complex and cells expressing this mutant have impaired WASH association with endosomes. This affects the acting-dependent trafficking of the ATG9A-containing endosomes and reduces heterotypic fusion events [33].

The CALM (also known as PICALM) gene is within a well validated locus which has been associated with increased risk for Alzheimer's disease in genome-wide association studies [34, 35]. While the causative variant has not been established, there are suggestions that CALM expression is reduced in Alzheimer's disease brains [36-38]. CALM regulates the endocytosis of various SNAREs from the plasma membrane and these defects impact various stages of autophagy. Autophagosome biogenesis is compromised because of defective endocytosis of VAMP2, which affects homotypic fusion, as well 
as VAMP3, which regulates the heterotypic fusion. Autophagosome-degradation is impaired because of reduced endocytosis of VAMP8, which regulates autophagosome-lysosome fusion. This results in the accumulation of tau, an autophagy substrate which accumulates in Alzheimer's disease, where it is thought to be an important driver of pathology [39].

\section{Neurodevelopment and stem cell fate}

Recently, the degradation of Notch1 from the plasma membrane has been shown to be regulated by autophagy, in addition to its conventional endocytic route [40]. Enhanced autophagy increases Notch1 degradation and reduces its downstream signalling, while impairing autophagy via a range of genetic perturbations had the converse effects in cell culture and in vivo. Notch1 is endocytosed with ATG16L1 from the ATG16L1-containing coated pits where the vesicles containing both proteins traffic to recycling endosomes to meet ATG9A-containing vesicles in a VAMP3-dependent fashion. Thus, this plasma membrane protein is directly incorporated into autophagic precursor structures prior to the phagophore stage, and then enters the autophagosomes for degradation. Notch1 is an important regulator of stem cell fate and impaired conversion of stem cells to more differentiated types were seen in a range of tissues from an AT16L1 autophagy hypomorphic mouse model. For example, there was impaired neurogenesis from embryonic and adult neuronal stem cells in this model - this may contribute to pathology in diseases where there is modest autophagy compromise [40].

\section{Focal adhesion and tight junction turnover}

The degradation of components associated with the plasma membrane may also be mediated via autophagy receptors, which serve as a link between the relevant substrate protein and the components of the autophagosome, like LC3. Such a mechanism is important for the degradation of cell-matrix focal adhesions (FAs) when they are disassembled at the basal cell membrane. This process is 
thought to be largely mediated by the autophagy cargo receptor, neighbour of BRCA1 (NBR1) [41]. Recent studies have additionally shown that upon autophagy-induced Src activation, the disassembly and turnover of FAs depend on the direct interaction between the conserved LIR motif in the aminoterminal end of paxillin (an early precursor and important constituent of FAs) and LC3 [42]. These data may explain why autophagy is required for cell migration, invasion and metastasis, at least in the 4T1 orthotopic mouse mammary tumor model, in which 4T1 murine mammary carcinoma cells implanted into the mammary fat pad of syngeneic Balb/C mice [42].

As part of the lateral plasma membrane, adherens junctions (AJ) and tight junctions (TJ) function in controlling cell-cell adhesion and paracellular barrier functions, both required for maintaining cell polarity, a phenomenon lost upon epithelial mesenchymal transition (EMT) and tumor invasiveness [43]. Indeed, autophagy increases E-cadherin degradation (a major transmembrane component of AJ) and thus facilitates AJ dissolution during EMT [44]. Furthermore E-cadherin levels may be transcriptionally repressed in autophagy-deficient cells, where increased levels of p62 stabilise the oncogenic transcription factor Twist1, which supresses E-cadherin synthesis and potentiates EMT [45]. However, the molecular events involved in the process of autophagy-dependent AJ disassembly are not completely understood and likely involve other processes. For example, degradation of the TJ protein claudin-2 by autophagy leads to reduced epithelial TJ permeability with increased paracellular barrier properties, a phenomenon relevant to inflammatory bowel disease [46].

\section{Connexins and autophagy - a case of mutual regulation.}

Connexins are another group of lateral plasma membrane proteins which are degraded via autophagy. At present, it is not clear if they are directly incorporated into autophagic precursor structures like Notch1, or degraded via an autophagy receptor-like mechanism, like focal adhesions. However, what 
is striking is that there is a reciprocal regulation of autophagy by connexins [47]. Connexins localised to the plasma membrane inhibit autophagy by interacting with various proteins that regulate autophagosome biogenesis, like ATG16L1, VPS34, Beclin-1 and VPS15. When autophagy is induced by starvation, this effect is reversed by the arrival of ATG14 to this ATG-Connexin complex, which enables its internalization along with ATG9A. The resulting autophagic degradation of the connexions reduces the levels of these inhibitory proteins, thereby enabling more long-lasting autophagy activation [47].

\section{Ciliogenesis-autophagy interplay}

Another mechanism of mutual regulation links autophagy to ciliogenesis. Starvation induces autophagy by relocalizing certain autophagy proteins (ATG16L1, AMBRA1, LC3, GABARAPL1) to cilia and thus promoting the increased cilia-plasma membrane turnover required for effective ciliogenesis. Ciliogenesis also upregulates autophagy, potentially enabling a self-sustaining feedforward mechanism: ciliogenesis-autophagy-ciliogenesis [48]. Recent studies have shown that mechanical stimuli such as fluid flow trigger and perpetuate this feedforward loop, as autophagy plays a central role in reducing cell size/shape that further accentuates ciliogenesis [49]. In this way, autophagy may respond to fluid flow in the kidney to regulate epithelial cell size [49].

\section{Conclusions}

Recent studies suggest multiple layers of regulation between the plasma membrane and its associated proteins and autophagy (Figure 2). On the one hand, autophagy proteins traffic via the plasma membrane to sites of autophagosome biogenesis and factors regulating their endocytosis impact autophagy. Then, SNAREs which regulate key fusion steps in autophagy are regulated by endocytosis. Importantly, autophagy can also regulate cell fate by influencing the degradation of proteins that impact differentiation, like Notch1 or proteins that affect migration. 
Finally, connexins provide an example of how an autophagy inhibitory machinery at the plasma membrane can itself be degraded by autophagy, thereby providing an autoregulatory positive feedback which can boost many aspects of autophagy. 
Figure 1. Plasma membrane contribution to autophagosome biogenesis.

The plasma membrane represents an important source of ATG9A and ATG16L1 vesicles [13-15]. ATG9A is internalized in clathrin coated pits and delivered to recycling endosomes (RE) through the conventional transferrin receptor internalization route via early endosomes (EE) [14, 25]. ATG16L1 also interacts with AP2-clathrin structures at the plasma membrane [13]. However, the pool of clathrin coated vesicles containing ATG16L1 is distinct from that containing ATG9A, and do not follow the conventional internalization pathway, being directly delivered to recycling endosomes [14]. The heterotypic fusion of ATG9A- and ATG16L1-positive vesicles in the RE is mediated by VAMP3, which is attached to ATG9A-positive vesicles in early endosomes [14]. The homotypic fusion between ATG16L1 vesicles is mediated by different SNARE complexes, such as the plasma membrane-derived SNARE, VAMP7 [15]. Upon starvation, annexin A2 expression is induced by cJUN activation to facilitate both the ATG9A sorting from early endosomes to recycling endosomes [29] and the homotypic fusion of ATG16L1-positive vesicles through recruiting phosphatidylserine and phosphatidylinositides [30]. The phagophores evolve towards autophagosomes that ultimately fuse with lysosomes and form autolysosomes.

\section{Figure 2. Physiological relevance for plasma membrane contribution to autophagy.}

Upon autophagy induction, (1) Notch1 [40] and (2) cilium factors (GLI1/2) [48] traffic together with ATG16L1 to be delivered and degraded by autophagy. At the plasma membrane, (3) connexins require ATG9 to be delivered to autophagosomes for degradation [47]. Focal adhesion disassembly is mediated by autophagy by increased paxillin degradation through either (4a) direct paxillin-NBR1 interaction [41] or (4b) direct paxillin-LC3 interaction upon Src activation [42]. Autophagy upregulation also degrades (5) tight junction proteins (claudin2) [46] and (6) adherens junctions proteins (E-cadherins) [44] through yet unclarified routes. Autophagy inhibition increases the levels of p62 which stabilize Twist1 in the nucleus to transcriptionally repress E-cadherin expression [45].

\section{Acknowledgements}

DCR is grateful for funding from the Wellcome Trust (Principal Research Fellowship to 095317/Z/11/Z), and a Wellcome Trust Strategic Grant to Cambridge Institute for Medical Research $(100140 / \mathrm{Z} / 12 / \mathrm{Z})$ 


\section{REFERENCES}

1. Biazik, J., Yla-Anttila, P., Vihinen, H., Jokitalo, E. \& Eskelinen, E. L. (2015) Ultrastructural relationship of the phagophore with surrounding organelles, Autophagy. 11, 439-51.

2. Bento, C. F., Renna, M., Ghislat, G., Puri, C., Ashkenazi, A., Vicinanza, M., Menzies, F. M. \& Rubinsztein, D. C. (2016) Mammalian Autophagy: How Does It Work?, Annual review of biochemistry. 85, 685-713.

3. Jahreiss, L., Menzies, F. M. \& Rubinsztein, D. C. (2008) The itinerary of autophagosomes: from peripheral formation to kiss-and-run fusion with lysosomes, Traffic. 9, 574-87.

4. Korolchuk, V. I., Saiki, S., Lichtenberg, M., Siddiqi, F. H., Roberts, E. A., Imarisio, S., Jahreiss, L., Sarkar, S., Futter, M., Menzies, F. M., O'Kane, C. J., Deretic, V. \& Rubinsztein, D. C. (2011) Lysosomal positioning coordinates cellular nutrient responses, Nature cell biology. 13, 453-60.

5. Axe, E. L., Walker, S. A., Manifava, M., Chandra, P., Roderick, H. L., Habermann, A., Griffiths, G. \& Ktistakis, N. T. (2008) Autophagosome formation from membrane compartments enriched in phosphatidylinositol 3-phosphate and dynamically connected to the endoplasmic reticulum, $J$ Cell Biol. 182, 685-701.

6. Hayashi-Nishino, M., Fujita, N., Noda, T., Yamaguchi, A., Yoshimori, T. \& Yamamoto, A. (2009) A subdomain of the endoplasmic reticulum forms a cradle for autophagosome formation, Nature cell biology. 11, 1433-7.

7. Yla-Anttila, P., Vihinen, H., Jokitalo, E. \& Eskelinen, E. L. (2009) 3D tomography reveals connections between the phagophore and endoplasmic reticulum, Autophagy. 5, 1180-5.

8. Hailey, D. W., Rambold, A. S., Satpute-Krishnan, P., Mitra, K., Sougrat, R., Kim, P. K. \& Lippincott-Schwartz, J. (2010) Mitochondria supply membranes for autophagosome biogenesis during starvation, Cell. 141, 656-67.

9. Hamasaki, M., Furuta, N., Matsuda, A., Nezu, A., Yamamoto, A., Fujita, N., Oomori, H., Noda, T., Haraguchi, T., Hiraoka, Y., Amano, A. \& Yoshimori, T. (2013) Autophagosomes form at ERmitochondria contact sites, Nature. 495, 389-93.

10. Geng, J., Nair, U., Yasumura-Yorimitsu, K. \& Klionsky, D. J. (2010) Post-Golgi Sec proteins are required for autophagy in Saccharomyces cerevisiae, Molecular biology of the cell. 21, 2257-69.

11. Graef, M., Friedman, J. R., Graham, C., Babu, M. \& Nunnari, J. (2013) ER exit sites are physical and functional core autophagosome biogenesis components, Molecular biology of the cell. 24, 29182931.

12. Zoppino, F. C. M., Militello, R. D., Slavin, I., Alvarez, C. \& Colombo, M. I. (2010) Autophagosome Formation Depends on the Small GTPase Rab1 and Functional ER Exit Sites, Traffic. 11, 1246-1261.

13. Ravikumar, B., Moreau, K., Jahreiss, L., Puri, C. \& Rubinsztein, D. C. (2010) Plasma membrane contributes to the formation of pre-autophagosomal structures, Nature cell biology. 12, 747-57.

14. Puri, C., Renna, M., Bento, C. F., Moreau, K. \& Rubinsztein, D. C. (2013) Diverse autophagosome membrane sources coalesce in recycling endosomes, Cell. 154, 1285-99.

15. Moreau, K., Ravikumar, B., Renna, M., Puri, C. \& Rubinsztein, D. C. (2011) Autophagosome precursor maturation requires homotypic fusion, Cell. 146, 303-17.

16. Weidberg, H., Shvets, E., Shpilka, T., Shimron, F., Shinder, V. \& Elazar, Z. (2010) LC3 and GATE-16/GABARAP subfamilies are both essential yet act differently in autophagosome biogenesis, The EMBO journal. 29, 1792-802.

17. Tanida, I., Ueno, T. \& Kominami, E. (2004) LC3 conjugation system in mammalian autophagy, The international journal of biochemistry \& cell biology. 36, 2503-18. 
18. Tanida, I., Sou, Y. S., Ezaki, J., Minematsu-Ikeguchi, N., Ueno, T. \& Kominami, E. (2004) HsAtg4B/HsApg4B/autophagin-1 cleaves the carboxyl termini of three human Atg8 homologues and delipidates microtubule-associated protein light chain 3- and GABAA receptor-associated proteinphospholipid conjugates, The Journal of biological chemistry. 279, 36268-76.

19. Tanida, I., Tanida-Miyake, E., Komatsu, M., Ueno, T. \& Kominami, E. (2002) Human Apg3p/Aut1p homologue is an authentic E2 enzyme for multiple substrates, GATE-16, GABARAP, and MAP-LC3, and facilitates the conjugation of hApg12p to hApg5p, The Journal of biological chemistry. 277, 13739-44.

20. Hanada, T., Noda, N. N., Satomi, Y., Ichimura, Y., Fujioka, Y., Takao, T., Inagaki, F. \& Ohsumi, Y. (2007) The Atg12-Atg5 conjugate has a novel E3-like activity for protein lipidation in autophagy, The Journal of biological chemistry. 282, 37298-302.

21. Kabeya, Y., Mizushima, N., Ueno, T., Yamamoto, A., Kirisako, T., Noda, T., Kominami, E., Ohsumi, Y. \& Yoshimori, T. (2000) LC3, a mammalian homologue of yeast Apg8p, is localized in autophagosome membranes after processing, The EMBO journal. 19, 5720-8.

22. Knorr, R. L., Lipowsky, R. \& Dimova, R. (2015) Autophagosome closure requires membrane scission, Autophagy. 11, 2134-2137.

23. Moreau, K., Ravikumar, B., Puri, C. \& Rubinsztein, D. C. (2012) Arf6 promotes autophagosome formation via effects on phosphatidylinositol 4,5-bisphosphate and phospholipase D, J Cell Biol. 196, 483-96.

24. Orsi, A., Razi, M., Dooley, H. C., Robinson, D., Weston, A. E., Collinson, L. M. \& Tooze, S. A. (2012) Dynamic and transient interactions of Atg9 with autophagosomes, but not membrane integration, are required for autophagy, Molecular biology of the cell. 23, 1860-73.

25. Popovic, D. \& Dikic, I. (2014) TBC1D5 and the AP2 complex regulate ATG9 trafficking and initiation of autophagy, EMBO reports. 15, 392-401.

26. Knaevelsrud, H., Soreng, K., Raiborg, C., Haberg, K., Rasmuson, F., Brech, A., Liestol, K., Rusten, T. E., Stenmark, H., Neufeld, T. P., Carlsson, S. R. \& Simonsen, A. (2013) Membrane remodeling by the PX-BAR protein SNX18 promotes autophagosome formation, J Cell Biol. 202, 331-49.

27. Lamb, C. A., Nuhlen, S., Judith, D., Frith, D., Snijders, A. P., Behrends, C. \& Tooze, S. A. (2016) TBC1D14 regulates autophagy via the TRAPP complex and ATG9 traffic, The EMBO journal. 35, 281-301.

28. Shirahama-Noda, K., Kira, S., Yoshimori, T. \& Noda, T. (2013) TRAPPIII is responsible for vesicular transport from early endosomes to Golgi, facilitating Atg9 cycling in autophagy, Journal of cell science. 126, 4963-73.

29. Moreau, K., Ghislat, G., Hochfeld, W., Renna, M., Zavodszky, E., Runwal, G., Puri, C., Lee, S., Siddiqi, F., Menzies, F. M., Ravikumar, B. \& Rubinsztein, D. C. (2015) Transcriptional regulation of Annexin A2 promotes starvation-induced autophagy, Nature communications. 6, 8045.

30. Morozova, K., Sridhar, S., Zolla, V., Clement, C. C., Scharf, B., Verzani, Z., Diaz, A., Larocca, J. N., Hajjar, K. A., Cuervo, A. M. \& Santambrogio, L. (2015) Annexin A2 promotes phagophore assembly by enhancing Atg16L(+) vesicle biogenesis and homotypic fusion, Nature communications. 6, 5856.

31. Vilarino-Guell, C., Wider, C., Ross, O. A., Dachsel, J. C., Kachergus, J. M., Lincoln, S. J., SotoOrtolaza, A. I., Cobb, S. A., Wilhoite, G. J., Bacon, J. A., Behrouz, B., Melrose, H. L., Hentati, E., Puschmann, A., Evans, D. M., Conibear, E., Wasserman, W. W., Aasly, J. O., Burkhard, P. R., Djaldetti, R., Ghika, J., Hentati, F., Krygowska-Wajs, A., Lynch, T., Melamed, E., Rajput, A., Rajput, A. H., Solida, A., Wu, R. M., Uitti, R. J., Wszolek, Z. K., Vingerhoets, F. \& Farrer, M. J. (2011) VPS35 mutations in Parkinson disease, American journal of human genetics. 89, 162-7. 
32. Zimprich, A., Benet-Pages, A., Struhal, W., Graf, E., Eck, S. H., Offman, M. N., Haubenberger, D., Spielberger, S., Schulte, E. C., Lichtner, P., Rossle, S. C., Klopp, N., Wolf, E., Seppi, K., Pirker, W., Presslauer, S., Mollenhauer, B., Katzenschlager, R., Foki, T., Hotzy, C., Reinthaler, E., Harutyunyan, A., Kralovics, R., Peters, A., Zimprich, F., Brucke, T., Poewe, W., Auff, E., Trenkwalder, C., Rost, B., Ransmayr, G., Winkelmann, J., Meitinger, T. \& Strom, T. M. (2011) A mutation in VPS35, encoding a subunit of the retromer complex, causes late-onset Parkinson disease, American journal of human genetics. 89, 168-75.

33. Zavodszky, E., Seaman, M. N., Moreau, K., Jimenez-Sanchez, M., Breusegem, S. Y., Harbour, M. E. \& Rubinsztein, D. C. (2014) Mutation in VPS35 associated with Parkinson's disease impairs WASH complex association and inhibits autophagy, Nature communications. 5, 3828.

34. Jun, G., Naj, A. C., Beecham, G. W., Wang, L. S., Buros, J., Gallins, P. J., Buxbaum, J. D., Ertekin-Taner, N., Fallin, M. D., Friedland, R., Inzelberg, R., Kramer, P., Rogaeva, E., St GeorgeHyslop, P., Alzheimer's Disease Genetics, C., Cantwell, L. B., Dombroski, B. A., Saykin, A. J., Reiman, E. M., Bennett, D. A., Morris, J. C., Lunetta, K. L., Martin, E. R., Montine, T. J., Goate, A. M., Blacker, D., Tsuang, D. W., Beekly, D., Cupples, L. A., Hakonarson, H., Kukull, W., Foroud, T. M., Haines, J., Mayeux, R., Farrer, L. A., Pericak-Vance, M. A. \& Schellenberg, G. D. (2010) Metaanalysis confirms CR1, CLU, and PICALM as alzheimer disease risk loci and reveals interactions with APOE genotypes, Arch Neurol. 67, 1473-84.

35. Harold, D., Abraham, R., Hollingworth, P., Sims, R., Gerrish, A., Hamshere, M. L., Pahwa, J. S., Moskvina, V., Dowzell, K., Williams, A., Jones, N., Thomas, C., Stretton, A., Morgan, A. R., Lovestone, S., Powell, J., Proitsi, P., Lupton, M. K., Brayne, C., Rubinsztein, D. C., Gill, M., Lawlor, B., Lynch, A., Morgan, K., Brown, K. S., Passmore, P. A., Craig, D., McGuinness, B., Todd, S., Holmes, C., Mann, D., Smith, A. D., Love, S., Kehoe, P. G., Hardy, J., Mead, S., Fox, N., Rossor, M., Collinge, J., Maier, W., Jessen, F., Schurmann, B., Heun, R., van den Bussche, H., Heuser, I., Kornhuber, J., Wiltfang, J., Dichgans, M., Frolich, L., Hampel, H., Hull, M., Rujescu, D., Goate, A. M., Kauwe, J. S., Cruchaga, C., Nowotny, P., Morris, J. C., Mayo, K., Sleegers, K., Bettens, K., Engelborghs, S., De Deyn, P. P., Van Broeckhoven, C., Livingston, G., Bass, N. J., Gurling, H., McQuillin, A., Gwilliam, R., Deloukas, P., Al-Chalabi, A., Shaw, C. E., Tsolaki, M., Singleton, A. B., Guerreiro, R., Muhleisen, T. W., Nothen, M. M., Moebus, S., Jockel, K. H., Klopp, N., Wichmann, H. E., Carrasquillo, M. M., Pankratz, V. S., Younkin, S. G., Holmans, P. A., O'Donovan, M., Owen, M. J. \& Williams, J. (2009) Genome-wide association study identifies variants at CLU and PICALM associated with Alzheimer's disease, Nature genetics. 41, 1088-93.

36. Hollingworth, P.Harold, D.Sims, R.Gerrish, A.Lambert, J. C.Carrasquillo, M. M.Abraham, R.Hamshere, M. L.Pahwa, J. S.Moskvina, V.Dowzell, K.Jones, N.Stretton, A.Thomas, C.Richards, A.Ivanov, D.Widdowson, C.Chapman, J.Lovestone, S.Powell, J.Proitsi, P.Lupton, M. K.Brayne, C.Rubinsztein, D. C.Gill, M.Lawlor, B.Lynch, A.Brown, K. S.Passmore, P. A.Craig, D.McGuinness, B.Todd, S.Holmes, C.Mann, D.Smith, A. D.Beaumont, H.Warden, D.Wilcock, G.Love, S.Kehoe, P. G.Hooper, N. M.Vardy, E. R.Hardy, J.Mead, S.Fox, N. C.Rossor, M.Collinge, J.Maier, W.Jessen, F.Ruther, E.Schurmann, B.Heun, R.Kolsch, H.van den Bussche, H.Heuser, I.Kornhuber, J.Wiltfang, J.Dichgans, M.Frolich, L.Hampel, H.Gallacher, J.Hull, M.Rujescu, D.Giegling, I.Goate, A. M.Kauwe, J. S.Cruchaga, C.Nowotny, P.Morris, J. C.Mayo, K.Sleegers, K.Bettens, K.Engelborghs, S.De Deyn, P. P.Van Broeckhoven, C.Livingston, G.Bass, N. J.Gurling, H.McQuillin, A.Gwilliam, R.Deloukas, P.Al-Chalabi, A.Shaw, C. E.Tsolaki, M.Singleton, A. B.Guerreiro, R.Muhleisen, T. W.Nothen, M. M.Moebus, S.Jockel, K. H.Klopp, N.Wichmann, H. E.Pankratz, V. S.Sando, S. B.Aasly, J. O.Barcikowska, M.Wszolek, Z. K.Dickson, D. W.Graff-Radford, N. R.Petersen, R. C., et al. (2011) Common variants at ABCA7, MS4A6A/MS4A4E, EPHA1, CD33 and CD2AP are associated with Alzheimer's disease, Nature genetics. 43, 429-35.

37. Lambert, J. C., Zelenika, D., Hiltunen, M., Chouraki, V., Combarros, O., Bullido, M. J., Tognoni, G., Fievet, N., Boland, A., Arosio, B., Coto, E., Del Zompo, M., Mateo, I., Frank-Garcia, A., Helisalmi, S., Porcellini, E., Pilotto, A., Forti, P., Ferri, R., Delepine, M., Scarpini, E., Siciliano, G., Solfrizzi, V., Sorbi, S., Spalletta, G., Ravaglia, G., Valdivieso, F., Alvarez, V., Bosco, P., Mancuso, M., Panza, F., Nacmias, B., Bossu, P., Piccardi, P., Annoni, G., Seripa, D., Galimberti, D., Licastro, 
F., Lathrop, M., Soininen, H. \& Amouyel, P. (2011) Evidence of the association of BIN1 and PICALM with the AD risk in contrasting European populations, Neurobiol Aging. 32, 756 e11-5.

38. Schjeide, B. M., Schnack, C., Lambert, J. C., Lill, C. M., Kirchheiner, J., Tumani, H., Otto, M., Tanzi, R. E., Lehrach, H., Amouyel, P., von Arnim, C. A. \& Bertram, L. (2011) The role of clusterin, complement receptor 1, and phosphatidylinositol binding clathrin assembly protein in Alzheimer disease risk and cerebrospinal fluid biomarker levels, Archives of general psychiatry. 68, 207-13.

39. Moreau, K., Fleming, A., Imarisio, S., Lopez Ramirez, A., Mercer, J. L., Jimenez-Sanchez, M., Bento, C. F., Puri, C., Zavodszky, E., Siddiqi, F., Lavau, C. P., Betton, M., O'Kane, C. J., Wechsler, D. S. \& Rubinsztein, D. C. (2014) PICALM modulates autophagy activity and tau accumulation, Nature communications. 5, 4998.

40. Wu, X., Fleming, A., Ricketts, T., Pavel, M., Virgin, H., Menzies, F. M. \& Rubinsztein, D. C. (2016) Autophagy regulates Notch degradation and modulates stem cell development and neurogenesis, Nature communications. 7, 10533.

41. Kenific, C. M., Stehbens, S. J., Goldsmith, J., Leidal, A. M., Faure, N., Ye, J., Wittmann, T. \& Debnath, J. (2016) NBR1 enables autophagy-dependent focal adhesion turnover, J Cell Biol. 212, 577-90.

42. Sharifi, M. N., Mowers, E. E., Drake, L. E., Collier, C., Chen, H., Zamora, M., Mui, S. \& Macleod, K. F. (2016) Autophagy Promotes Focal Adhesion Disassembly and Cell Motility of Metastatic Tumor Cells through the Direct Interaction of Paxillin with LC3, Cell reports. 15, 1660-72.

43. Lamouille, S., Xu, J. \& Derynck, R. (2014) Molecular mechanisms of epithelial-mesenchymal transition, Nature reviews Molecular cell biology. 15, 178-96.

44. Pang, M., Wang, H., Rao, P., Zhao, Y., Xie, J., Cao, Q., Wang, Y., Wang, Y. M., Lee, V. W., Alexander, S. I., Harris, D. C. \& Zheng, G. (2016) Autophagy links beta-catenin and Smad signaling to promote epithelial-mesenchymal transition via upregulation of integrin linked kinase, The international journal of biochemistry \& cell biology. 76, 123-34.

45. Qiang, L., Zhao, B., Ming, M., Wang, N., He, T. C., Hwang, S., Thorburn, A. \& He, Y. Y. (2014) Regulation of cell proliferation and migration by p62 through stabilization of Twist1, Proceedings of the National Academy of Sciences of the United States of America. 111, 9241-6.

46. Nighot, P. K., Hu, C. A. \& Ma, T. Y. (2015) Autophagy enhances intestinal epithelial tight junction barrier function by targeting claudin-2 protein degradation, The Journal of biological chemistry. 290, 7234-46.

47. Bejarano, E., Yuste, A., Patel, B., Stout, R. F., Jr., Spray, D. C. \& Cuervo, A. M. (2014) Connexins modulate autophagosome biogenesis, Nature cell biology. 16, 401-14.

48. Pampliega, O., Orhon, I., Patel, B., Sridhar, S., Diaz-Carretero, A., Beau, I., Codogno, P., Satir, B. H., Satir, P. \& Cuervo, A. M. (2013) Functional interaction between autophagy and ciliogenesis, Nature. 502, 194-200.

49. Orhon, I., Dupont, N., Zaidan, M., Boitez, V., Burtin, M., Schmitt, A., Capiod, T., Viau, A., Beau, I., Wolfgang Kuehn, E., Friedlander, G., Terzi, F. \& Codogno, P. (2016) Primary-ciliumdependent autophagy controls epithelial cell volume in response to fluid flow, Nature cell biology. 18, 657-67. 


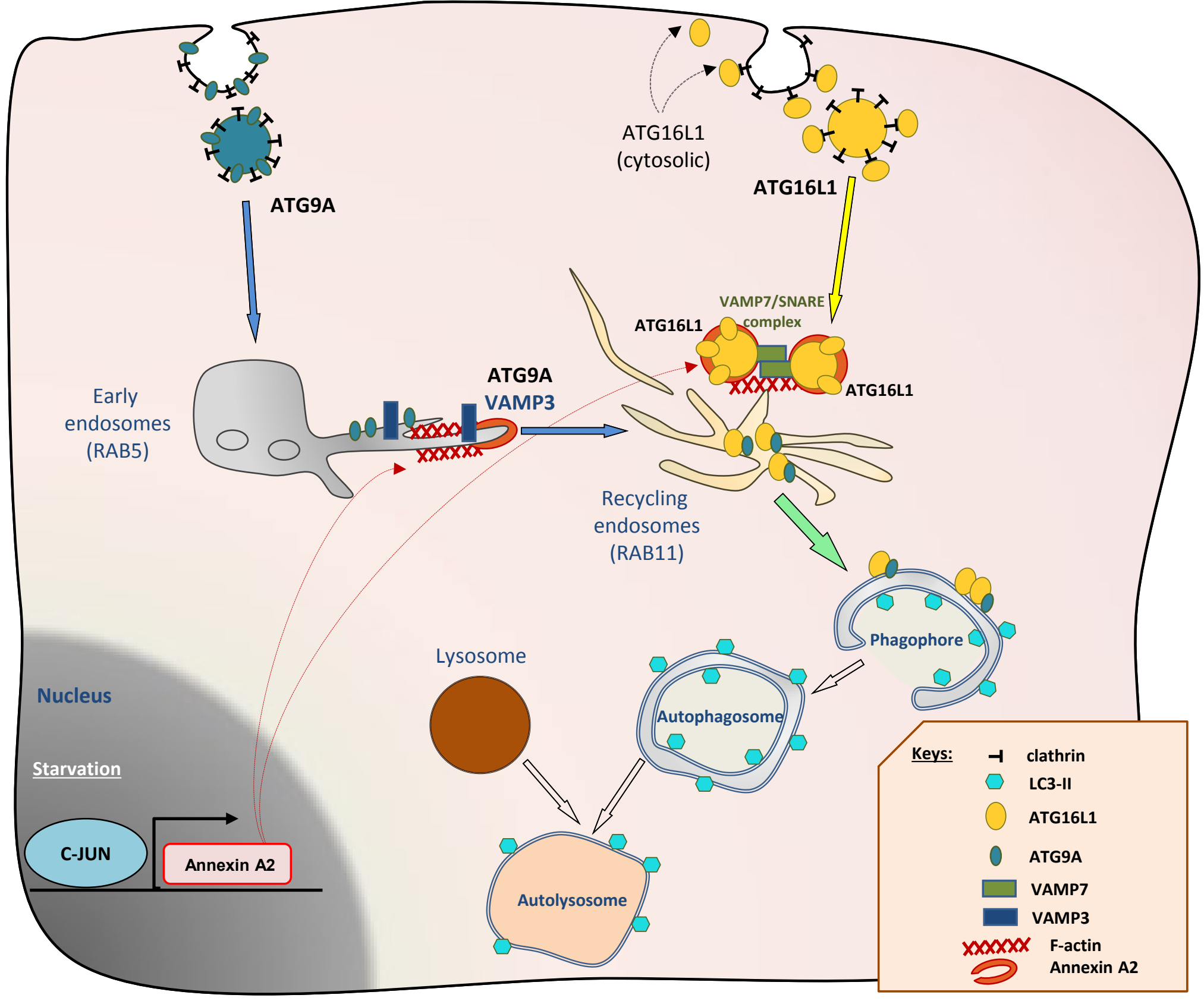




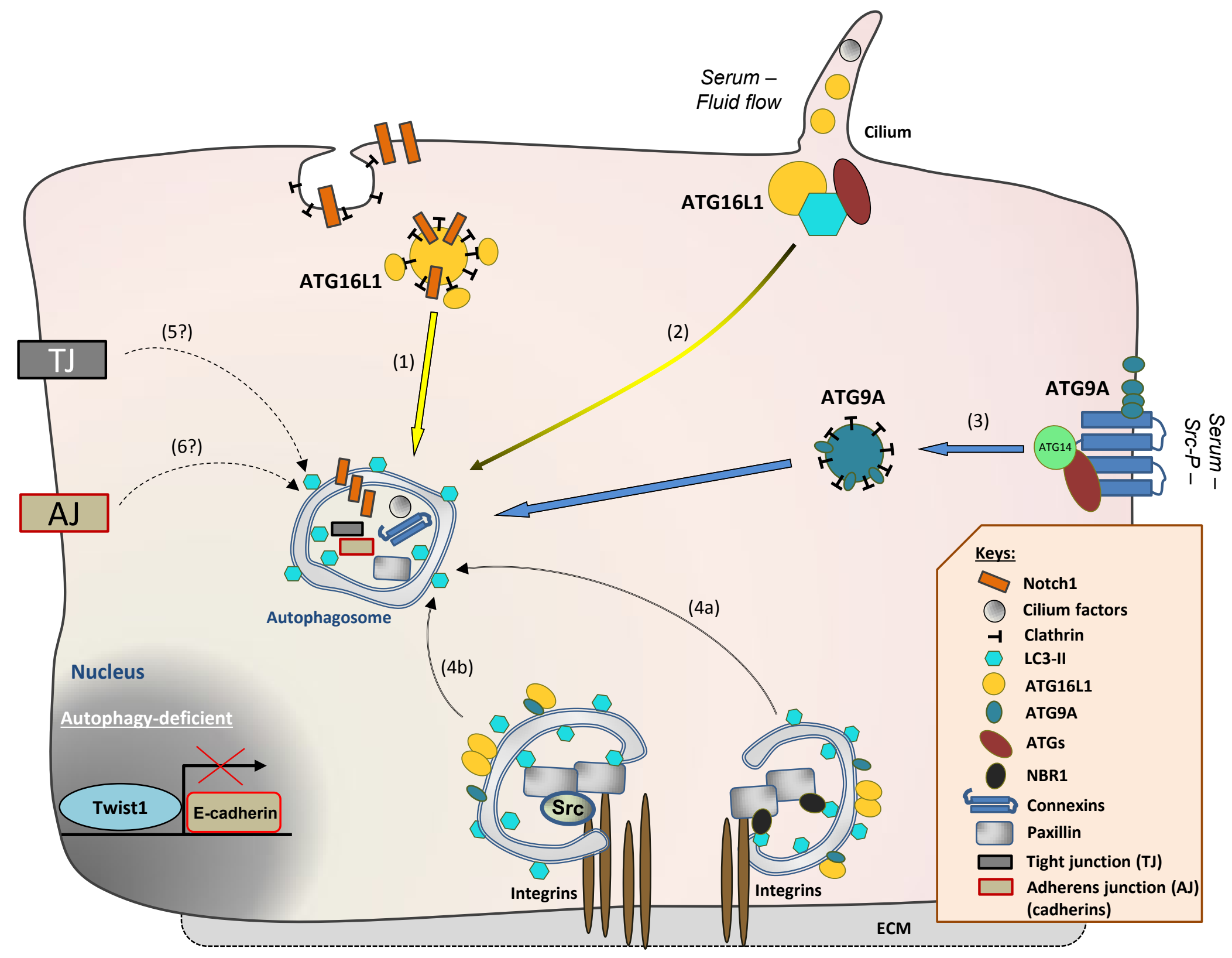

